\title{
Principals, Agents and Prisoners: An Economical Perspective on Information Systems Development Practice
}

\author{
Karlheinz Kautz and Bjarke Nielsen \\ Copenhagen Business School, Department of Informatics, \\ Frederiksberg, Denmark
}

\author{
Karl.Kautz@cbs.dk Bjarke.Nielsen@tiscali.dk
}

\begin{abstract}
Information systems development takes place within an economical context. However, the economical conditions, which shape systems development in practice, are hardly researched. In this paper we are investigating the question how a given price structure influences systems development projects. Our analysis is based on a multi case study and a Grounded Theory inspired research approach. Our work is informed by economic theories, which deal with the relationship of suppliers and customers and their mutual dependency. We thus apply principal-agent theory and economic game theory in form of the prisoner's dilemma. As a result we provide three interlinked models for understanding the impact of pricing structure on systems development practice. The main elements of these models are pricing structure, risk distribution and price level, and opportunistic behavior. We discuss how these elements are interrelated and examine their impact on information systems development in practice.
\end{abstract}

Keywords: information systems development, pricing structure, principal-agent theory, prisoner's dilemma.

\section{Introduction}

Information systems development takes place within an economical context. Cost overruns are frequently reported and the delivery of information systems within appropriate time and cost limits has even been given as one justification for the utilization of information systems development methodologies (Avison \& Fitzgerald, 1995). However, the economical conditions, which shape systems development practice are - beyond studies of IT service outsourcing (see for an overview f. ex. Dibbern, Goles, Hirschheim, \& Jayatilka, 2004; Lacity \& Hirschheim, 1993) - rarely researched by the information systems and the software engineering communities.

The term software economics has been coined by the software engineering community (Boehm \& Sullivan), which mostly concentrates on questions related to effort estimation (see f. ex. Boehm,

Material published as part of this publication, either on-line or in print, is copyrighted by the Informing Science Institute. Permission to make digital or paper copy of part or all of these works for personal or classroom use is granted without fee provided that the copies are not made or distributed for profit or commercial advantage AND that copies 1) bear this notice in full and 2) give the full citation on the first page. It is permissible to abstract these works so long as credit is given. To copy in all other cases or to republish or to post on a server or to redistribute to lists requires specific permission and payment of a fee. Contact Publisher@InformingScience.org to request redistribution permission.
1981, Boehm et al. 1995, Jørgensen \&

Carelius, 2004; Jørgensen \& Grimstad, 2005; Jørgensen, Teigen, \& MoløkkenØstvold, 2004).

Ciborra (1996) takes a contractual view on information systems development and based on transaction cost theory discusses the market, bureaucracy and hierarchy, and the clan with their differing levels of trust and task uncertainty as 
a basis for different forms of systems development approaches. A number of other IS-related studies (see f. ex. Ang \& Beath, 1993; Banerjee \& Duflo, 2000; Banker \& Kemerer, 1992; Richmond \& Seidelmann, 1993; Richmond, Seidmann, \& Whinston, 1992; Wang, Baron, \& Seidmann, 1997; Whang, 1992) describe features of contracts, contract types and pricing structures and investigate their economical role, but do not relate them to actual systems development practice.

Lichtenstein and McDonnell (2003) and Lichtenstein (2004) are an exception. Considering software development as outsourcing and based on an economical perspective they formulate a number of hypotheses about the relationship between frequency of milestones, project risk, uncertainty and price structure as determined in systems development contracts, but they do not obtain any clear results.

Sabherwal (1999) and Bjerknes and Mathiassen (2000) discuss the antithetic relation between trust and control with regard to supplier-customer interactions and contracts. Based on this work a case study carried out by Madsen and Kautz (2002) found that information systems development encounters difficulties when performed in an iterative way acknowledging uncertainty, but according to a fixed price contract.

On this background we studied how a given price structure affects information systems development in practice. We collected data in a multi case study and applied economic theories, which deal with the relationship of suppliers and customers and their mutual dependency, namely principal-agent theory and economic game theory in form of the prisoner's dilemma. As our investigation is a first attempt of understanding the relationship between pricing structure and systems development in practice it is exploratory and we have limited it to the development of new information systems for a particular customer.

The remainder of the paper is structured as follows: Section 2 presents our research method and section 3 describes our theoretical background. In section 4 we provide our research findings in form of three interrelated models explaining the impact of pricing structure on systems development practice. We finish with discussing implications and conclusions in the sections 5 and 6.

\section{Research Method}

Our research question implies that we are investigating how practice behaves instead of investigating if practice behaves in a specific way. Because of its explorative and emergent nature, our study leaves us with no specific hypothesis and advocates an open method. Thus, we adopted an approach with many explanatory variables. Without hypotheses to be verified or invalidated, the data collection had to be more extensive than a search for the impact of already known factors and implied that our study would be narrower without a number of observation units. We therefore opted for a multiple case study. Based on our experience from earlier studies (Hansen \& Kautz, 2005; Kautz, Hansen, \& Jacobsen, 2004; Kjærgaard \& Kautz, 2005) we chose an analysis, which utilizes an approach inspired by the Grounded Theory methodology (Glaser \& Strauss, 1967; Strauss \& Corbin, 1998). As there exists no specific theory on contract types, pricing structure and systems development in practice Grounded Theory is particularly appropriate as it does not require an existing theory, on the contrary it grounds an emerging theory on the collected data. To secure the validity of our work we largely followed Klein and Myers's (1999) seven principles for interpretive field research and Eisenhardt's (1989) seven steps for case study research.

The data collection is based on twelve semi-structured qualitative interviews with representatives from 7 companies. To avoid any sector or product specific bias we chose organizations, which covered as diverse sectors as aerospace, banking \& finance, media \& advertisement, health and public administration and which provide content management, document handling, e-business, 
process management and many other kinds of information systems. The sample includes companies with as few as 10 employees as well as 40000 employees. The companies were between 6 and 40 years old. As the project aimed at understanding the impact of a chosen price structure on systems development projects we were interested in data from those stakeholders involved in the tasks spanning from the actual sales to the delivery of the final product. Thus, we interviewed 2 sales personnel, 4 project managers and 6 developers across the different companies with 3 to 25 years of experience in the field. The questions in the individual interviews were based on existing literature within the subject, and for this purpose we worked out interview guides for the individual interviews. As we worked with semi-structured interviews, the interview guide was used as a checklist for issues that had to be covered during the interview and not as an actual outline for the interviews. The nature of the interviews had been open, and when the conversation moved towards new and interesting areas relevant to the subject, we pursued and probed the new directions. All interviews lasted between 60 and 75 minutes and were tape recorded and transcribed. The interviewees had the opportunity to see and approve the transcripts.

With the collected data from the interviews we performed an analysis based on Grounded Theory. The Grounded Theory framework describes a way to search relevant topics and relations through three sequential steps: the purpose of open coding is to open the data material. This is done by looking for different meanings in the statements and classifying part-statements with labels to explain the meanings of the different parts. The result is a range of different codes and concepts comprising the thoughts, ideas and meanings of the text. The purpose of axial coding is to find the categories into which the discovered codes/concepts can be classified. The meanings behind the concepts are compared and categorized in main and subcategories or concepts, which together present patterns or a set of axes to explain the data material and relationships between the concepts. Thus, the located axes reflect the parameters that are important for the study's subject. Based on the axes categories, the purpose of selective coding is to explain relationships and contexts to refine the overall explanation into a coherent picture of the observations. The overall picture is based on central categories and represents a complete framework of explanations for the field in focus.

In general, we can describe our approach as follows: In parallel with the actual data collection during the interviews, we reflected on possible categories and relations and in a brainstorm session after the $4^{\text {th }}$ interview, we wrote down our first impressions and ideas. With the results from the brainstorm in mind, we afterwards performed the remaining interviews, transcribed them all and then read and coded the transcribed interviews and subsequently gathered the codes. Subsequently, we searched for coincidences and patterns in the codes and evaluated them in relation to each other. In this way, we achieved a general picture of the statements from the interviews grouped around important axes and categories in the data material. Next, we arranged the categories into main and subcategories and described and explained the main categories based on the data material. Informed by economic theory we identified three main categories, which were mutually related to each other, and as a final result we developed three interlinked models, which explain the mutual impact of pricing structure and systems development in practice. These are described in the following. First, we however introduce the theoretical background in more detail.

\section{Theoretical Background}

Although no specific theory relating pricing structure and systems development in practice exists, by taking an economic perspective, our study is informed by the existing literature and in particular by economic writings concerning pricing structures and theories of supplier-customer relationships.

As such Ciborra's (1996) work on transaction cost theory with its possible implications for information systems development and use builds the general background for our study. With regard 
to pricing the literature distinguishes between fixed price and time and material approaches and variations of these such as fixed price with payment for extra efforts or time and material with an upper limit (see f. ex. Overby, Vang, \& Mahnke, 2003).

With regard to the relationship between suppliers and customers principal-agent theory provided a suitable background for our study. It describes how a principal, a customer, should build up an incentive structure, a pricing structure or scheme, to achieve a desired behavior from an agent, a supplier. Principal-agent theory is based on the assumption that people do not always fulfill the contracts and do not always stick to the agreements they have made. Such behavior, which might lead to advantages at the expense of others, is called opportunistic behavior (Douma \& Schreuder, 2002). Characteristic for opportunistic behavior is that only some people and also they only some times, exhibit it. It is difficult, if not impossible to distinguish honest from dishonest people before they actually show opportunistic behavior. Principal-agent theory deals with the avoidance of opportunistic behavior. In this context two concepts are important, namely risk, in particular the possibility of loss, and here especially the suppliers' relationship to risk, and observability, in particular the customers' possibility to observe a supplier.

The prisoner's dilemma is a behavioral theory, which formalizes situations of mutual dependency such as those of principals and agents and it is part of the economical game theory (Douma \& Schreuder, 2002). The classical prisoner's dilemma can be illustrated by the situation to arrested suspects of a crime find themselves in. If both of them confess the crime they will be sentenced for 5 years each. They also know that if they are silent they can not be imprisoned for more than 3 years and they have made deal that they will not confess to minimize their sentence. During the interrogation the police create a mutual dependency between them by offering them a deal. If one testifies for the prosecution against the other and this one remains silent or denies the crime, this accomplice receives a 6 year sentence and the betrayer will get 1 year for a minor charge. The aim of the police with the mutual dependency is to create a dilemma for the suspects and thus the basis for mistrust. Complete trust between the suspects and thus both silence and rejection of the police's offer will result in the lowest joint degree of penalty. However the dilemma for both suspects is, that independently of what the other chooses, they would be better off admitting the crime. Thus there is an incentive to act opportunistically. The police hope that both suspects are tempted to show opportunistic behavior, which means they will break their contract and seek a personal advantage at the expense of the other. If this happens both of them will be sentenced for 5 years each. In a more general form the theory can be used to characterize co-operation and deviation from a contract, also termed as opportunistic behavior by two business partners, where cooperation of both parties is considered a win-win situation, co-operation of one party and deviation from the contract as a win-loose or loose win situation, respectively and a situation where both parties deviate from the contract as a loose-loose situation. There, the following four outcomes can be distinguished: Punishment for the naivety to co-operate (PN), Reward for cooperation (RC), Temptation to act opportunistically (TO), and Punishment for mutually opportunistic behavior (PO). This leads to the situation described in Table 1:

Table 1: The Prisoner's Dilemma

\begin{tabular}{|c|c|c|c|}
\hline & \multicolumn{2}{|c|}{ Business Partner 1} \\
\hline & & Co-operation & $\begin{array}{l}\text { Deviation } \\
\text { from Contract }\end{array}$ \\
\hline \multirow[b]{2}{*}{$\begin{array}{l}\text { Business } \\
\text { Partner } 2\end{array}$} & Co-operation & $\mathrm{RC}, \mathrm{RC}$ & PN, TO \\
\hline & $\begin{array}{l}\text { Deviation } \\
\text { from Contract }\end{array}$ & TO, PN & PO, PO \\
\hline
\end{tabular}


The model depicted in Table 1 is based on the subsequent relationship between the four outcomes: Punishment for the nativity to co-operate $<$ Punishment for mutually opportunistic behavior $<$ Reward for co-operation $<$ Temptation to act opportunistically, where

- Punishment for the nativity to co-operate < Punishment for mutually opportunistic behavior means that the reward to act opportunistically is larger, in case one partner acts opportunistically;

- Punishment for mutually opportunistic behavior < Reward for co-operation means that the reward for mutually opportunistic behavior is smaller than the reward for mutual cooperation;

- Reward for co-operation < Temptation to act opportunistically means that the reward to act opportunistically is larger, in case the other partner co-operates.

\section{Findings}

As a background for our further analysis we identified the pricing structures our respondents used during the contract negotiations and realisation of new systems development projects. In line with the literature we found the following pricing structures. A fixed price comprises all costs of a development project and the suppliers' profit depends on their ability to provide the desired system within time and budget. With its origin in a given task with fixed scope, a fixed deadline and a fixed price, fixed price with payment for extra effort contains an explicit mechanism for dealing with changed or additional requirements. Time and material bills the actual effort, while time and material with an upper limit sets a threshold for the maximum expenses. Finally, we came across a $5^{\text {th }}$ structure called framework agreements. Framework agreements comprise a maximum number of hours, for which a customer can book a supplier within a given time frame. This might give a customer a lower price per hour and gives both parties the liberty to negotiate the actual use of the hours according to all available pricing structures.

\section{Suppliers as Agents and Customers as Principals}

Applying principal-agent theory, we recognize customers as principals and suppliers as agents, and a model (see Figure 1) describing the relationship of opportunistic behavior, risk distribution and price level and the choice of pricing structure emerged from the data.

Pricing structures have an embedded distribution of risk between both the supplier and the customer. Choice of pricing structure has an impact on risk distribution and price level. Fixed price contracts shift the risk to the supplier. If, in contrast a time and material pricing structure is used, the risk moves to the customer. We found that the suppliers are rather risk averse, thus the price level increases with risk supplements, which reflect the risks that the suppliers perceive.

Distribution of risk and price level has an impact on the opportunistic behavior, which both suppliers and customers show. When suppliers carry the risk their opportunistic behavior is derived from the experienced time pressure they work under to reach the deadline. They might then try to fulfil the customers' requirements with as little functionality as possible and sometimes even leave out some of them. They might also insist on the requirement specification as originally developed and not accept any changes of the requirements after the contract was signed. In any case, the supplier compromises the functionality of the product to be delivered as well as the customer expectations and as such the system's quality. When the customer carries the risk, the suppliers' behavior is influenced by the fact that their earnings will be higher the more time they use for an assignment. Thus, project management sometimes relaxes with regard to keeping deadlines, and progress and the customers' effort are not steered and monitored to the same extent as if the suppliers themselves carry the risk. Suppliers also extend and let the scope of a project slip by experimenting with new functionality and even technology. Unauthorised further development 


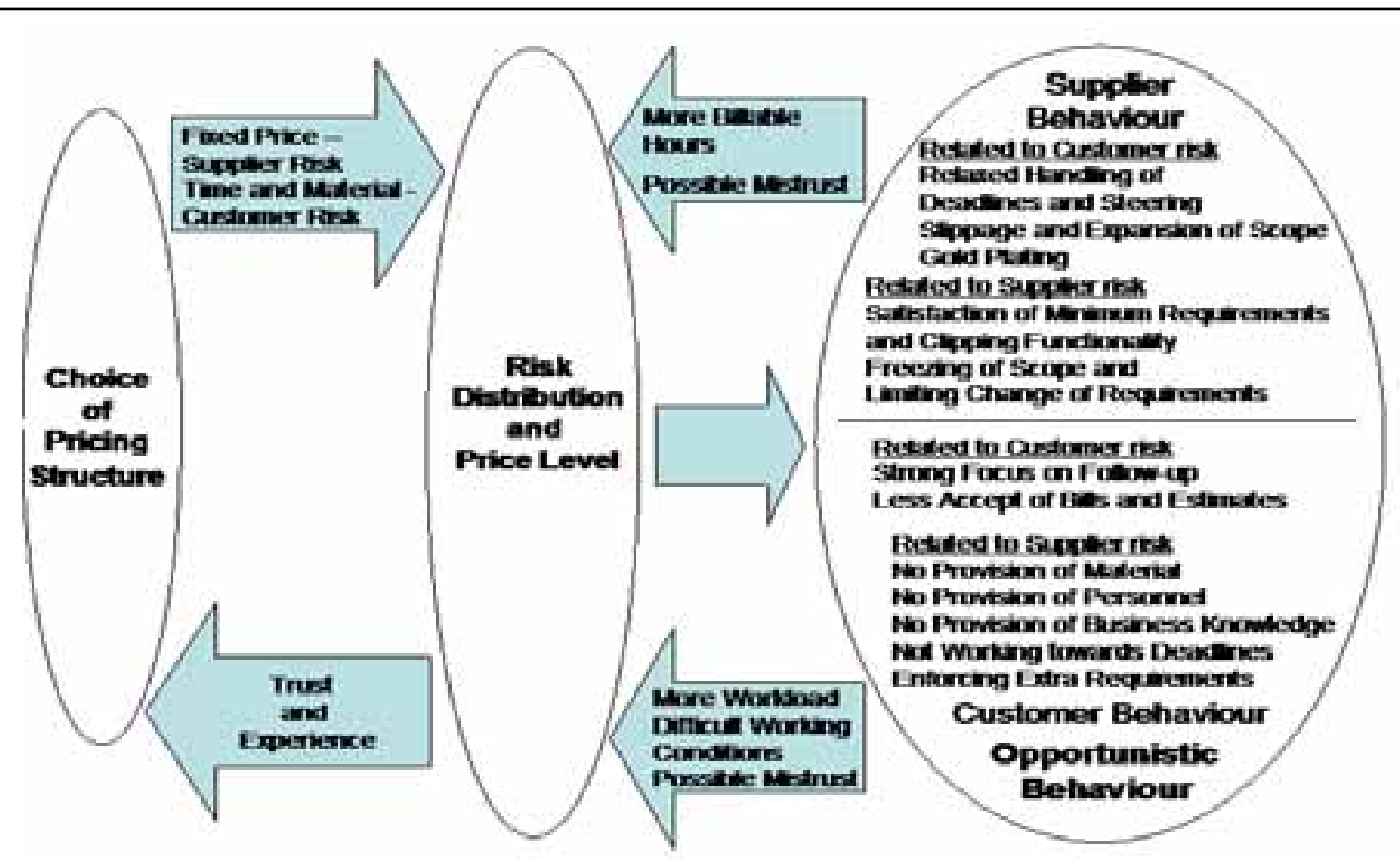

Figure 1: Model of the Mutual Impact of Pricing Structure and Systems Development Practice

and attempts for perfection, known as gold plating, happen more often. Ultimately, the customers might not get the systems they want and as a consequence might choose another supplier in the future. The customers' opportunistic behavior differs depending on which party is carrying the risk. When the suppliers hold the risk, their earnings depend on the customers' efforts. However, suppliers experience that they are not provided by the customer with the material, the personnel and the business knowledge they need. They also complain that the customers do not work dedicatedly towards agreed deadlines and that they try to press new requirements into the projects. This is a problem for them, because denying these demands might have an impact on future business with the customer, while accepting them results in extra hours, time pressure and changes of deadlines. When the customers themselves carry the risk they tend to demand more documentation with regard to the hours the suppliers use in the project, which leads to larger administrative expenses for those. In addition, customers are to a lesser extent appreciative of the suppliers' use of time, which sometimes results in a reluctance to pay for the suppliers' efforts. In that situation it can be hard for the suppliers to collect the charges for some provided development work.

The suppliers' and customers' behavior in return has an impact on the distribution of the risk between the two parties and on the price for a project. As described above lacking customer efforts might lead to increased workload and economical strain for the suppliers and relaxed project steering and handling of deadlines might cause more billable hours and thus higher costs for the customer. The same is true for slippage and expansion of scope as well as for gold plating.

The customers' experiences from previous projects with regard to distribution of risk and price level have an impact on the choice of pricing structure for future projects. The basis for trust is created when suppliers live up to the customers' expectations, which means that the customers will be more willing to choose a pricing structure, where they carry more of the risk. However, when suppliers abuse this trust either by decreasing functionality or raising prices, mistrust develops and customers will not accept the same degree of risk in future projects. 
As principal-agent theory describes how a principal, the customer should put together a reward structure, i.e. pricing structure, to achieve the desired behavior from an agent, the supplier, in this context observability of the suppliers' efforts plays an important role. The customers are usually not able to observe the suppliers' efforts directly and often realise that it is too expensive and unrealistic, f. ex. as project leaders in severe technical projects, to directly observe the suppliers. They therefore leave the management of the projects to the suppliers, but then demand some signals as indication for the actual effort. The suppliers also see the necessity to send these signals and meet the demanding by providing them in form of project plans and follow-ups.

In order to give the supplier the biggest possible incentive to deliver an effective effort, this puts the customers in a situation where they can choose between shifting the risk over to the supplier in form of demanding a fixed price contract or remunerating the supplier in accordance with the provided signals. The choice between these two possibilities is made on the basis of the extra costs, which are implied by a shift of risk.

\section{Suppliers and Customers as Prisoners}

The above analysis has shown a mutual dependency of the suppliers and the customers. Applying the prisoner's dilemma we can now illustrate, which behavior leads to what the suppliers and the customers experience as win-loose and loose-win situations. When the suppliers carry the risk (see Table 2), customers experience fulfillment of minimum requirements and the clipping of functionality as well as the freezing of scope and limitation of requirement changes as opportunistic supplier behavior, in which they loose and the suppliers win. When they hold the risk themselves the suppliers experience the customer behavior of no provision of material, no provision of personnel and no provision business knowledge as well as those not working towards deadlines and enforcing extra requirement as opportunistic behavior with a win for the customers and a loss for the supplier.

Table 2: Opportunistic Behavior and Win-Loose/Loose Win Situation during Supplier Risk

\begin{tabular}{|c|c|c|c|}
\hline \multirow{2}{*}{\multicolumn{2}{|c|}{ Supplier Risk }} & \multicolumn{2}{|c|}{ Customer } \\
\hline & & \multirow[t]{2}{*}{ Co-operation } & $\begin{array}{l}\text { Opportunistic } \\
\text { Behavior }\end{array}$ \\
\hline \multirow{2}{*}{ Supplier } & Co-operation & & $\begin{array}{l}\text { No Provision of Material } \\
\text { No Provision of Personnel } \\
\text { No Provision of Business } \\
\text { Knowledge } \\
\text { Not Working towards Dead- } \\
\text { lines } \\
\text { Enforcing Extra Require- } \\
\text { ments }\end{array}$ \\
\hline & $\begin{array}{l}\text { Opportunistic } \\
\text { Behavior } \\
\text { Win-Loose/ } \\
\text { Loose-Win } \\
\text { Situation }\end{array}$ & $\begin{array}{l}\text { Satisfaction of Minimum } \\
\text { Requirements and Clipping } \\
\text { Functionality } \\
\text { Freezing of Scope and } \\
\text { Limiting Change of } \\
\text { Requirements }\end{array}$ & \\
\hline
\end{tabular}


When the customers carry the risk (see Table 3) they see relaxed handling of deadlines and steering, slippage and expansion of scope and gold plating as a win for the suppliers and a loss for themselves while the suppliers see the customers' strong focus on follow-ups and the lesser accept of bills and estimates as a loose-win situation for themselves. If none of the parties show opportunistic behavior they will achieve a win-win situation, if they both show opportunistic behavior they will end up in a loose-loose situation. This is described in more detail below.

Table 3: Opportunistic Behavior and Win-Loose/Loose Win Situation during Customer Risk

\begin{tabular}{|c|c|c|c|}
\hline \multirow{2}{*}{\multicolumn{2}{|c|}{ Customer Risk }} & \multicolumn{2}{|c|}{ Customer } \\
\hline & & \multirow[t]{2}{*}{ Co-operation } & $\begin{array}{l}\text { Opportunistic } \\
\text { Behavior }\end{array}$ \\
\hline \multirow[b]{2}{*}{ Supplier } & Co-operation & & $\begin{array}{l}\text { Strong Focus on Follow-up } \\
\text { Less Accept of Bills and } \\
\text { Estimates }\end{array}$ \\
\hline & $\begin{array}{l}\text { Opportunistic } \\
\text { Behavior } \\
\text { Win-Loose/ } \\
\text { Loose-Win } \\
\text { Situation }\end{array}$ & $\begin{array}{l}\text { Relaxed Handling of } \\
\text { Deadlines and Steering } \\
\text { Slippage and Expansion of } \\
\text { Scope } \\
\text { Gold Plating }\end{array}$ & \\
\hline
\end{tabular}

The opportunistic behavior of both suppliers and customers has a number of impacts (see table 4). Dependant on which of the parties shows opportunistic behavior it can lead to an increase of costs and price, changes in the product functionality, scope and ultimately quality or an reimbursed or non-reimbursed increase of the supplier's development expenses. Opportunistic behavior might also lead to mistrust between the parties. However, in cases where both parties observe the terms of earlier contracts, are they able to build up trust to each other and hereby create the possibility to co-operate under a less strict framework. Suppliers and customers experience a mutual dependency which satisfies the conditions of the general model for the prisoner's dilemma. This means that the collective benefit will be highest when both parties co-operate to reach a win-win situation. In such a situation the customers will get a product, which satisfies their expectations and with the quality as agreed in the contract. Likewise, the suppliers will get the earnings as agreed in the contract and both parties will develop trust to each other. 
Table 4: Ultimate Consequences of Opportunistic Behavior

\begin{tabular}{|c|c|c|c|}
\hline & \multicolumn{2}{|c|}{ Customer } \\
\hline & & Co-operation & Opportunistic Behavior \\
\hline \multirow[t]{2}{*}{ Supplier } & Co-operation & $\begin{array}{l}\text { Supplier: } \\
\text { Earnings as agreed in contract } \\
\text { Trust in customer } \\
\text { Customer: } \\
\text { Product quality as agreed in } \\
\text { contract } \\
\text { Trust in Supplier }\end{array}$ & $\begin{array}{l}\text { Supplier: } \\
\text { Minimization of earnings } \\
\text { Mistrust in customer } \\
\text { Customer: } \\
\text { Maximization of product } \\
\text { quality }\end{array}$ \\
\hline & $\begin{array}{l}\text { Opportunistic } \\
\text { Behavior }\end{array}$ & $\begin{array}{l}\text { Supplier: } \\
\text { Maximization of earnings } \\
\text { Customer: } \\
\text { Minimization of product quality } \\
\text { Mistrust in supplier }\end{array}$ & $\begin{array}{l}\text { Supplier: } \\
\text { Minimization of earnings } \\
\text { Mistrust in customer } \\
\text { Customer: } \\
\text { Minimization of product } \\
\text { quality } \\
\text { Mistrust in supplier }\end{array}$ \\
\hline
\end{tabular}

The relationship between suppliers and customers is however characterized by the temptation, which each party experience, to think or work towards achieving a win-loose situation. In case the suppliers work towards such a situation and the customers work towards a win-win situation, the suppliers will be able to maximize the earnings from the respective project. The profit will be of such a magnitude that the suppliers will earn more from the project by acting opportunistically than they would earn in a win-win situation for that one project. This happens at the expense of the customers, who either get a product, which does not meet their expectations, has lesser functionality and thus quality or has to pay more. In any case the customers develop mistrust.

If, in contrast, the customers work for a win-loose situation and the suppliers for a win-win situation, the customers will experience a fulfillment of their expectations and the quality of the product. The maximization will have such an extent that the customer will achieve a better system by acting opportunistically than by working for a win-win situation. This happens at the expense of the supplier, who will be forced to use more resources and thus will have a smaller profit for that respective project as agreed. It will however also lead to mistrust by supplier for the customer.

Finally, when both parties act opportunistically, they end up in a loose-loose situation. Both parties will gain less than in a win-win situation. Beyond less profit for the suppliers, less product quality and fewer fulfilled expectations for the customer, both parties will also develop a mutual mistrust for each other.

The win-loose and loose-loose situations are characterized by that one or both parties think 'me' and 'them', while in a win-win situation both parties think 'we' and 'us' and take care of the mutual dependency and relationship and work to achieve their shared objectives. 


\section{Implications}

Our analysis and our models of the mutual impact of pricing structures and information systems development practice show that suppliers and customers are mutually dependant on that none of the parties shows opportunistic behavior to secure that the suppliers' earnings and the customers' expectations concerning the systems' functionality and ultimately quality turn into what was agreed upon in the contract.

In line with Bjerknes and Mathiassen (2000), who found that while trust promotes creativity and mutual learning, necessary elements of systems development, contracts promote decisions and monitoring of progress according to the agreement we argue that to enhance practice it is necessary to reconsider the customer-supplier relationship and to change the current form of pricing structures and contract. This argument is supported by Madsen and Kautz's (2002) case study which indicates that iterative development with its explicit focus on learning is problematic, when information systems development has to be performed according to a fixed price contract. Ciborra (1996) has argued that if task uncertainty, as is often the case in information systems development, is high the most efficient work arrangement is one based on a high level of trust. The question then arises how to handle the contradiction between trust and control and how to develop trust.

We agree with Highsmith (2002) who promotes as one way of creating trust what he calls 'delivered-feature' contracts and pricing structures, where the supplier makes operational features available to the customer at the end of each iterative delivery cycle. They provide visibility and observability and allow for the continuous determination of value, and of the contract, but they require a development approach and model that support short iterations as promoted more recently under the label agile software development (Cockburn, 2002; Highsmith, 2000), but already advocated since more then a decade known as f. ex. evolutionary systems development (Budde, Kautz, Kuhlenkamp, \& Züllighoven, 1992).

\section{Conclusions}

Our study demonstrates the merits of principal-agent theory and the prisoner's dilemma for the information systems development research and confirms the literature on pricing structures, but goes beyond reporting the mere distribution of the different contract types and pricing structures as well as abstract economic reflections.

The analysis of the pricing structures' influence on information systems development practice has provided new insights and resulted in three explanatory models of the phenomenon, describing 1) the mutual influence of pricing structures and information systems development practice 2) the involved parties' perception of opportunistic behavior as win-loose/loose-win situations, and 3) the ultimate consequences of opportunistic behavior.

The models contribute with a cumulative treatment of the interrelationship of pricing structures, distribution of risk, price level and the opportunistic behavior of suppliers and customers. This provides a solid basis for future studies. We have limited our study to the development of new information systems and excluded operation, maintenance and further development as well as the development and adjustment of off-the-shelf products and have not researched whether there is any relationship between particular pricing structures and development models. These issues and the defendable limitation - as we were in particular interested in their perspective - that we only interviewed supplier and not customer organizations should be considered when performing future investigations. 


\section{References}

Ang, S. \& Beath, C. M. (1993). Hierarchical elements in software contracts. Journal of Organisational Computing, 3(3), 329-361.

Avison, D.E., \& Fitzgerald, G. (1995). Information systems development: Methodologies, techniques and tools. Maidenhead, UK: McGraw-Hill.

Banerjee, A. \& Duflo, E. (2000). Reputation effects and the limits of contracting: A study of the Indian software industry. Quarterly Journal of Economics, 15(3), 989-1017.

Banker, R. D. \& Kemerer, C. F. (1992). Performance evaluation metrics for information systems development: A principal-agent model. Information Systems Research, 3(4), 379-401.

Bjerknes G. \& Mathiassen L. (2000). Improving the customer-supplier relation in IT development, In Proceedings of the 33rd Hawaii International Conference on Systems Sciences (HICSS-33).

Boehm, B. W. (1981). Software engineering economics. Prentice Hall.

Boehm, B. W. \& Sullivan, K. J. (2000). Software economics: A roadmap. In Proceedings of the International Conference on Software Engineering, Conference on The Future of Software Engineering, IEEE-CS: Computer Society, Irish Computer Society, 319-343.

Boehm, B. W., Clark, B., Horowitz, E., Westland, J. C., Madachy, R. D. \& Selby, R. W. (1995). Cost models for future software life cycle processes: COCOMO 2.0. Annuals of Software Engineering, 1, 57-94.

Buddde, R., Kautz, K., Kuhlenkamp, K. \& Züllighoven, H. (1992). Prototyping -- An approach to evolutionary systems development. Berlin, Germany: Springer Verlag.

Ciborra, C. (1996). Teams, markets and systems. Cambridge, UK: Cambridge University Press.

Cockburn, A. (2002). Agile software development. Boston, USA: Addison-Wesley.

Dibbern, J., Goles, T., Hirschheim, R., \& Jayatilka, B. (2004). Information systems outsourcing: A survey and analysis of the literature. ACM SIGMIS Database, 35(4), 6-102.

Douma S. \& H. Schreuder (2002). Economic approaches to organizations ( $3^{\text {rd }}$ ed.). Prentice Hall.

Eisenhardt, K. M. (1989). Building theories from case study research. Academy of Management Review, 14(4), 532-550.

Glaser, B. G. \& Strauss, A. L. (1967). The discovery of grounded theory - Strategies for qualitative research. New York, USA: Aldine De Gruyter.

Hansen, B. \& Kautz, K. (2005). Grounded theory applied -Studying information systems development methodologies in practice. In Proceedings of the Hawaii International Conference on System Sciences (HICSS-38).

Highsmith, J. (2000). Adaptive software development: A collaborative approach to managing complex systems. New York, USA: Dorset House.

Highsmith, J. (2002). Agile software development ecosystems. Boston, USA: Addison-Wesley, Pearson Education.

Jørgensen, M. \& Carelius, C. G. (2004). An empirical study of software project bidding. IEEE Transactions of Software Engineering, 30(12), 953-969.

Jørgensen, M., Teigen, K. H. \& Moløkken-Østvold, K. J. (2004). Better sure than safe? Overconfidence in judgment based software development effort prediction intervals. Journal of Systems and Software, 70(1-2), 79-93.

Jørgensen, M. \& Grimstad, S. (2005).Over-optimism in software development projects: "The winner's curse”. In Proceedings of IEEE ConieleComp, Puebla, Mexico. IEEE Society Press, pp. 280-285.

Kautz, K., Hansen, B. \& Jacobsen, D. (2004). The utilization of information systems development methodologies in practice. Journal of Information Technology Cases and Applications, 6 (4). 
Kjærgaard, A. \& Kautz, K. (2005). Knowledge management as an autonomous venturing process: A process model of establishing knowledge management. In Proceedings of the International Conference on Information Systems, Las Vegas, USA, December 11 - 14, 2005

Klein, H. \& Myers, M. (1999). A set of principles for conducting and evaluating interpretive field studies in information systems. MIS Quarterly, 23(1), 67-93.

Lacity, M.C. \& Hirschheim, R. (1993). The information systems outsourcing bandwagon. Sloan Management Review, Fall, 73-86.

Lichtenstein, Y. \& McDonnell, A. (2003). Pricing software development services. In Proceedings of the European Conference on Information Systems, Naples, Italy, June 16 -21, 2005.

Lichtenstein, Y. (2004) Puzzles in software development contracting. Communication of the ACM, 47(2), 61-65.

Madsen, S. \&Kautz, K. (2002). Applying system development methods in practice - The RUP example. In Proceedings of $11^{\text {th }}$ International Conference on Information Systems Developments, Methods \& Tools - Theory \& Practice, Riga, Latvia, September, 12-14, 2002.

Overby, M. L., Vang, J. \& Mahnke, V. (2003). Strategic IT outsourcing (In Danish), Copenhagen, DK: Thomsen.

Richmond, W., Seidmann, A. \& Whinston, A. (1992). Incomplete contracting issues in IS development outsourcing. Decision Support Systems, 8(5), 459-477.

Richmond, W. \& Seidmann, A. (1993). Software development outsourcing contract: Structure and business value. Journal of Management Information Systems, 10(1), 57-72.

Sabherwal, R. (1999). The role of trust in outsourced IS development projects. Communications of the ACM, 42 (2), 80-86.

Strauss, A. \& Corbin, J. (1998). Basics of qualitative research. London, UK: SAGE Publications.

Wang, E. T. G., Baron, T. \& Seidmann, A. (1997). Contracting structures for custom software development: The impacts of informational rents and uncertainty on internal development and outsourcing. Management Science, 43(12), 1726-1744.

Whang, S. (1992). Contracting for software development. Management Science, 38(3), 307-324.

\section{Biographies}

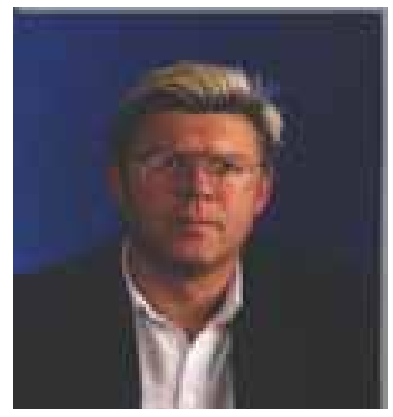

Karlheinz Kautz is professor in systems development and software engineering at the Department for Informatics He holds a PhD in systems development and MSc in software development. He is the chair of the IFIP TC 8 WG 8.6 on the adoption and diffusion of IT. His work has been published internationally on conferences and in journals including Information Systems Journal, Informing Science Journal, Information Technology and People, IEEE Software, Journal of IT Cases and Applications, Information and Software Technology, Scandinavian Journal of Information Systems, Journal of IT Education and Journal of Knowledge Management.

Bjarke Nielsen has been a student in the degree program in Computer Science and Business Administration at Copenhagen Business School and has been a research assistant for the project, which builds the basis for the research described here. 